\title{
GMR
}

\section{Thermotherapy-induced reduction in glioma invasiveness is mediated by tumor necrosis factor-alpha}

\author{
L.J. Qin ${ }^{1}$, T. Zhang ${ }^{1}$, Y.S. Jia ${ }^{2}$, Y.B. Zhang ${ }^{1}$, Y.X. Zhang ${ }^{1}$ and H.T. Wang ${ }^{1}$ \\ ${ }^{1}$ School of Basic Medical Sciences, \\ North China University of Science and Technology, Tangshan, China \\ ${ }^{2}$ College of Traditional Chinese Medicine, \\ North China University of Science and Technology, Tangshan, China \\ Corresponding authors: L.J. Qin / Y.X. Zhang \\ E-mail: qinlijuan_|@163.com / zhangyzx_|@163.com \\ Genet. Mol. Res. 14 (4): 11771-11779 (2015) \\ Received February 6, 2015 \\ Accepted June 17, 2015 \\ Published October 2, 2015 \\ DOI http://dx.doi.org/10.4238/2015.October.2.11
}

\begin{abstract}
Thermotherapy has been proven to be effective for the treatment of various tumors, including glioma. We determined whether tumor necrosis factor-alpha (TNF- $\alpha$ ) is involved in the regulation of the biological processes of glioma development. Reverse transcriptionpolymerase chain reaction (RT-PCR) and immunocytochemistry were used to investigate the levels of TNF- $\alpha$ mRNA and heat shock factor-1 (HSF1) protein, respectively, in glioma cells. Radioimmunoassay was used to dynamically monitor the contents of TNF- $\alpha$ in the nutrient fluid of C6 cells after thermotherapy treatment. Crystal violet staining was used to determine glioma invasiveness. The most obvious increases in HSF1 protein and TNF- $\alpha$ mRNA in C 6 cells were observed at 30 and 60 min after thermotherapy, respectively. In addition, the radioactivity of TNF- $\alpha$ in the culture fluid of the $\mathrm{C} 6$ cells reached a peak after 120 min of thermotherapy. In addition, glioma invasiveness decreased and the concentration of TNF- $\alpha$ reached a maximum after 120 min of thermotherapy. Our results show that the decrease in thermotherapy-mediated glioma invasiveness is due to the
\end{abstract}


accelerated release of TNF- $\alpha$, which could promote the release of HSF1 from neurospongioma cells.

Key words: Tumor necrosis factor- $\alpha$; TNF- $\alpha$; Heat shock factor-1; HSF1; Thermotherapy; Glioma invasiveness

\section{INTRODUCTION}

Gliomas are characterized by an intense local invasiveness that limits the usefulness of surgical resection (Cahill et al., 1996; Chatterjee et al., 2005). A new method to treat malignant glioma by thermotherapy has been used for patients with malignant glioma (Du et al., 2009). Thermotherapy is a comprehensive treatment that is gradually being recognized by clinicians; it has a characteristically precise role and has no known side effects (Iwasaki et al., 1993; Ivarsson et al., 2003; Gourgou et al., 2010; James et al., 2010). Increasing evidence suggests that there is an evident decrease in both tumor surgical relapse rate and mortality following thermotherapy treatment (Jurivich et al., 1995). Brain scans of human glioma patients have demonstrated that thermotherapy decreases glioma invasiveness (Livak and Schmittgen, 2001), although the detailed underlying mechanisms have not yet been clarified. Therefore, the pathophysiological mechanisms of thermotherapy-mediated decreases in glioma invasiveness warrant further investigation.

A previous study demonstrated that thermotherapy might decrease malignant glioma invasiveness through a tumor necrosis factor-alpha (TNF- $\alpha$ ) pathway (Stummer and Kamp, 2009). However, thermotherapy markedly decreases glioma invasiveness independently of thermotherapy pretreatment. Therefore, we hypothesize that thermotherapy might have a positive effect on heat shock protein 70 (HSP70) expression in glioma.

Heat shock factor-1 (HSF1) combines with the heat shock element (HSE), which lies in the upstream region of the HSP70 gene, to promote HSP70 transcription and expression (Schwerdt et al., 2008). Furthermore, there is an HSE sequence near the promoter in the TNF- $\alpha$ gene (Senthil and Harrison, 2009). Studies have demonstrated that TNF- $\alpha$ and thermotherapy can decrease glioma invasiveness (Suzuki et al., 2010). Consequently, we hypothesize that activated HSF1 affects the transcription of HSP70 and TNF- $\alpha$ genes together by combining with their HSE sequences, which might induce TNF- $\alpha$ gene activation and protein expression, and thereby decrease glioma invasiveness.

To test this hypothesis, we investigated using real-time reverse transcription polymerase chain reaction (RT-PCR) methods whether thermotherapy can induce the expression of TNF- $\alpha$ and HSF1 proteins in glioma cells. We also studied the effect of TNF- $\alpha$ on the decrease in glioma invasiveness decreases.

\section{MATERIAL AND METHODS}

\section{Cell culture and TNF- $\alpha$ radioactivity}

Rat C6 glioma cells (obtained from the Cell Center Department of the Chinese Academy of Medical Sciences) were grown in Dulbecco's Modified Eagle Medium (DMEM) F-12 (Gibco, Germany) supplemented with $1.5 \%$ heat-inactivated fetal bovine serum (10270-106, Hyclone, Thermo Fisher Scientific, Inc. Shanghai, China), 15\% horse serum, $100 \mathrm{U} / \mathrm{mL}$ penicillin, and $100 \mu \mathrm{g} / \mathrm{mL}$ streptomycin under standard culture conditions. When cells reached confluence, the 
medium was aspirated and fresh serum-free medium was added to the cells for $12 \mathrm{~h}$. The cells were then washed once with sterile phosphate-buffered saline, and fresh serum-free medium was added. $\mathrm{C} 6$ cells were subjected to thermotherapy at $42^{\circ} \mathrm{C}$ for $10,30,60,120,180$, or $240 \mathrm{~min}$, then the TNF- $\alpha$ radioactivity of the supernatants was detected using the radioimmunity method $(N=15)$.

\section{Animals implanted with $\mathrm{C} 6$ cells}

Adult male Wistar rats (180-220 g) were purchased from the Center for Experimental Animals of Hebei United University. All animal experiments were conducted in accordance with the National Institutes of Health Guide for the Care and Use of Laboratory Animals. Core temperature was maintained between 37 and $38^{\circ} \mathrm{C}$ using a heat lamp. In brief, rats were anesthetized with $10 \%$ chloral hydrate $\left(3.5 \mathrm{~mL} / \mathrm{kg}\right.$, ip) and subsequently received intracerebral injection of $1 \times 10^{6} \mathrm{C} 6$ cells in $10 \mu \mathrm{L}$ medium with $1.2 \%$ methylcellulose using a Hamilton syringe. The injection coordinates were $0.2 \mathrm{~mm}$ anterior to the bregma, $3 \mathrm{~mm}$ lateral to the midline, and into the caudate nucleus to a depth of $5.5 \mathrm{~mm}$. The $\mathrm{C} 6$ cells were maintained in a monolayer culture in DMEM/F-12 medium (Gibco) with $10 \%(\mathrm{v} / \mathrm{v})$ fetal calf serum. On the 14th day after tumor implantation, the rats were prepared for treatment.

\section{Immunocytochemistry of HSF1}

The C6 cells were fixed with $4 \%$ paraformaldehyde for immunocytochemistry. The cell smears were stained for immunocytochemistry with a rabbit polyclonal antibody anti-HSF1 (diluted 1:150, Santa Cruz Biotechnology, Inc., Shanghai, China) following standard procedures. For semiquantitative measurements of HSF1 density, the slides were photographed and measured using a computer-aided image analyzing system (Motic Images Advanced 3.2, Xiamen, China).

\section{Real-time RT-PCR analysis}

Total RNA was isolated from cell samples and purified using RNAout (TaKaRa Biotechnology Co., Japan), following the manufacturer instructions. Total RNA (500 ng per sample) was reverse-transcribed into cDNA in a $20 \mu \mathrm{L}$ reaction mixture using an iScript cDNA Synthesis Kit (Bio-Rad, Hercules, CA, USA) according to the manufacturer instructions. Real-time RT-PCR was conducted using iQ SYBR Green Supermix (Bio-Rad) in a 50- $\mu \mathrm{L}$ reaction mixture with the set of primers listed in Table 1. All sets of primers were tested on $0.9 \%$ agarose gel to confirm a single amplification product. The amplified products for TNF- $\alpha$ were directly cloned into the pCRII-Topo vector (Invitrogen, Paisley, Scotland, UK) and sequenced to confirm their identity. All the primer pairs were designed using the Accelrys Gene 2.0v software (Tokyo, Japan).

The real-time PCR was run on a MyiQ instrument (Bio-Rad) with a three-step cycling program as follows: an initial hot start for $5 \mathrm{~min}$ at $95^{\circ} \mathrm{C}$ followed by 40 cycles with a denaturation step of $15 \mathrm{~s}$ at $95^{\circ} \mathrm{C}$, an annealing step of $30 \mathrm{~s}$ at $55^{\circ} \mathrm{C}$, and an extension step of $30 \mathrm{~s}$ at $72^{\circ} \mathrm{C}$, with the optics on at the last step. In preparation of a melt curve, the samples were heated for 1 min at $95^{\circ} \mathrm{C}$ then cooled for $1 \mathrm{~min}$ at $55^{\circ} \mathrm{C}$, and the melt curve was executed in $10 \mathrm{~s}$ increments of $0.5^{\circ} \mathrm{C}$ with the temperature increasing from 55 to $95^{\circ} \mathrm{C}$ with the optics on. All the primers used were selected and tested for the described amplification conditions. Efficiency and consistency of the cDNA synthesis was determined by amplification of the rat $18 \mathrm{~S}$ gene as a control. For each 
round of amplification, only those samples that were within one cycle of difference with respect to the mean for $18 \mathrm{~S}$ were considered for further analysis. For each sample of a specific target gene, each cycle threshold was normalized with respect to 18S. Relative expression was determined using the $2^{-\Delta \Delta C t}$ method (Saito et al., 2005).

Table 1. Primer sequences used for real-time reverse transcription-polymerase chain reaction (RT-PCR).

\begin{tabular}{lllcc}
\hline Gene & Accession No. & Primer Sequence & Region (bp) & Product length (bp) \\
\hline TNF- $\alpha$ & NM_012675 & F: 5'-TCTTCTGTCTACTGAACTTCGGGG-3' & $284-365$ & 82 \\
18S & X01117 & R: 5'-ATGGAACTGATGAGAGGGAGCC-3' & \\
& & F: 5'-CCAGTAAGTGCGGGTCATAAGC-3' & $1605-1732$ & 83 \\
\hline
\end{tabular}

TNF- $\alpha=$ tumor necrosis factor- $\alpha$; $18 \mathrm{~S}=$ rat ribosomal RNA subunit; $F=$ forward; $\mathrm{R}=$ reverse; $b p=$ base pairs.

\section{In vitro migration assay}

The $\mathrm{C} 6$ cells were resuspended in DMEM F-12 containing $15 \%$ fetal calf serum to obtain a concentration of $10^{7}$ cells $/ \mathrm{mL}$ and placed $\left(10^{6}\right.$ cells/well) in the upper compartments of Transwell migration chambers (Corning Costar 3421, USA). The cells were then placed in an incubator at $42^{\circ} \mathrm{C}$ for $10,30,60,120,180$, or $240 \mathrm{~min}$; the $\mathrm{C} 6$ cells that migrated to the lower compartment were counted under a light microscope. The experiments were performed in triplicate, and migration was determined by calculating the percentage of migrating cells relative to input.

\section{Statistics analysis}

All statistical analyses were performed using the SigmaStat software (SPSS, Chicago, IL, USA). All data are reported as means \pm standard deviation. $\mathrm{P}<0.05$ was considered to be significant.

\section{RESULTS}

\section{Relative levels of TNF- $\alpha$ from $\mathbf{C} 6$ cells}

The content of TNF- $\alpha$ in the experimental groups was 2.90- to 6.15 -fold higher than in the control group; therefore, thermotherapy greatly enhanced the upregulation of TNF- $\alpha$. Specifically, thermotherapy greatly increased TNF- $\alpha$ after $120 \mathrm{~min}$ of treatment. The relative levels of TNF- $\alpha$ in the $10,30,60,120,180$, and $240 \mathrm{~min}$ thermotherapy groups were $4.21 \pm 0.02 \mu \mathrm{g} / \mathrm{L}, 7.47 \pm 0.39$ $\mu \mathrm{g} / \mathrm{L}, 12.05 \pm 0.66 \mu \mathrm{g} / \mathrm{L}, 16.23 \pm 0.85 \mu \mathrm{g} / \mathrm{L}, 10.64 \pm 0.79 \mu \mathrm{g} / \mathrm{L}$, and $8.52 \pm 0.28 \mu \mathrm{g} / \mathrm{L}$, respectively $(\mathrm{P}<0.05, \mathrm{P}<0.01)$, as shown in Table 2 . Our study demonstrated that thermotherapy has a direct effect on TNF-a level in C6 cells.

\section{Thermotherapy-induced expression of TNF- $\alpha$ in $\mathbf{C} 6$ cells}

The levels of TNF- $\alpha$ mRNA were 1.9- to 10.6-fold higher in the experimental groups than in the control group, and thermotherapy greatly increased TNF- $\alpha$ mRNA levels after 60 min. The relative levels of TNF- $\alpha$ mRNA in the 10, 30,60,120, 180, and 240 min thermotherapy groups were 
$18.4 \pm 0.1,59.3 \pm 0.2,120.0 \pm 0.5,98.3 \pm 0.5,86.2 \pm 0.7$, and $75.1 \pm 0.8$, respectively $(P<0.05, P$ $<0.01$ ), as shown in Figure $1 \mathrm{~A}$ and $\mathrm{B}$.

Table 2. Tumor necrosis factor-alpha (TNF- $\alpha$ ) content of $\mathrm{C} 6$ cell fluid subjected to thermotherapy (TT) at different time points ( $\mu \mathrm{g} / \mathrm{L}$, mean \pm standard deviation, $\mathrm{N}=15$ for each treatment time).

\begin{tabular}{lcccccc}
\hline & \multicolumn{5}{c}{ Times after HT treatment (min) } \\
\cline { 2 - 6 } Groups & 10 & 30 & 60 & 120 & 180 & 240 \\
\hline Concentration before TT & $2.19 \pm 0.06$ & $1.88 \pm 0.128$ & $34 \pm 0.12$ & $2.06 \pm 0.12$ & $1.87 \pm 0.05$ & $2.18 \pm 0.09$ \\
Concentration after TT & $6.40 \pm 0.05$ & $9.35 \pm 0.51^{*}$ & $14.39 \pm 0.96^{*}$ & $18.29 \pm 0.78^{\star *}$ & $12.51 \pm 0.84^{*}$ & $10.70 \pm 0.38^{*}$ \\
Relative levels of TNF- $\alpha$ & $4.21 \pm 0.02$ & $7.47 \pm 0.39$ & $12.05 \pm 0.66$ & $16.23 \pm 0.85$ & $10.64 \pm 0.79$ & $8.52 \pm 0.28$ \\
\hline
\end{tabular}

${ }^{*} \mathrm{P}<0.05,{ }^{* \star} \mathrm{P}<0.01$ after TT group versus before TT group.

A
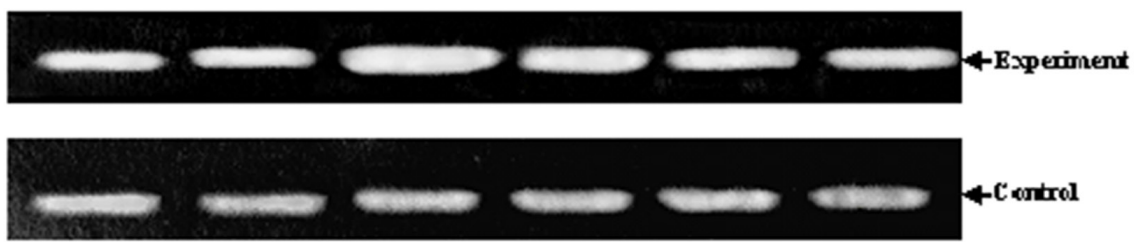

B

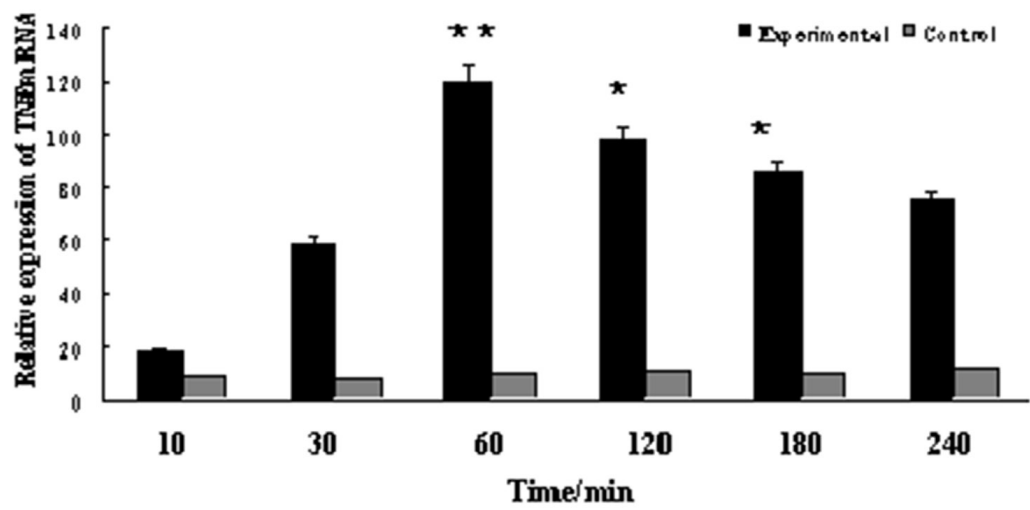

Figure 1. TNF- $\alpha$ mRNA levels in $C 6$ cells subjected to thermotherapy at different time points detected using RT-PCR. A. Agarose gel revealing the differences in TNF- $\alpha$ mRNA levels. B. Relative levels of TNF- $\alpha$ mRNA ( $=15$ for each time point) for the experimental and control groups. ${ }^{*} P<0.05$, ${ }^{* *} P<0.01$ versus control group.

\section{Thermotherapy-induced expression of TNF- $\alpha$ protein in the rat brain glioma model}

The content of TNF- $\alpha$ was small in the control group. Compared with the control group, the content of TNF- $\alpha$ in the rat brain glioma subjected to thermotherapy at various time points fluctuated with treatment time (Figure 2). The TNF- $\alpha$ content increased markedly after 60 min of thermotherapy. At 120 min, a significant increase in the radioactivity of TNF- $\alpha$ was noted, which was 15.0-fold higher than in the control group. The contents of TNF- $\alpha$ in the 10, 30, 60, 120, 180, and $240 \mathrm{~min}$ thermotherapy groups were $20.1 \pm 0.2 \mu \mathrm{g} / \mathrm{L}, 20.5 \pm 0.3 \mu \mathrm{g} / \mathrm{L}, 40.5 \pm 0.6 \mu \mathrm{g} / \mathrm{L}, 75.2 \pm 0.5$ $\mu \mathrm{g} / \mathrm{L}, 30.6 \pm 0.7 \mu \mathrm{g} / \mathrm{L}$, and $10.5 \pm 0.2 \mu \mathrm{g} / \mathrm{L}$, respectively $(P<0.05, P<0.01)$, as shown in Figure 2 


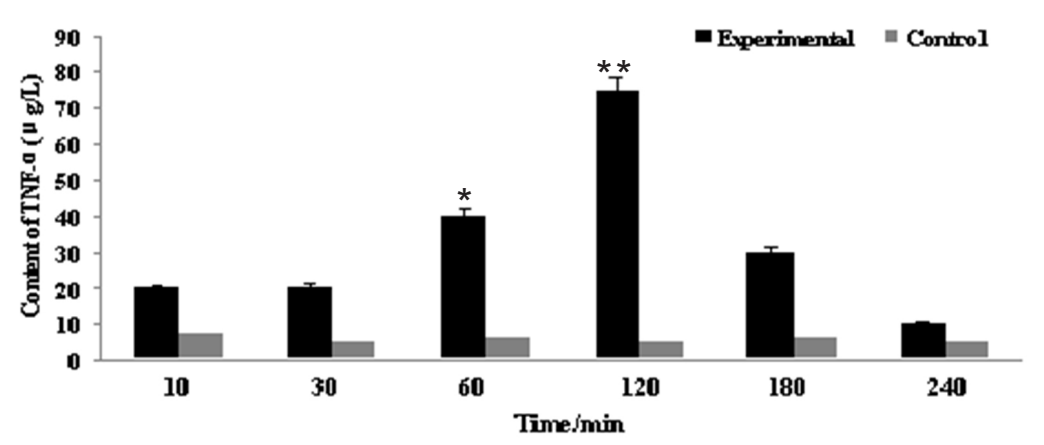

Figure 2. TNF- $\alpha$ content of glioma tissue subjected to thermotherapy at different time points $(\mathrm{N}=10$ for each time point). ${ }^{*} \mathrm{P}<0.05$ and ${ }^{* *} \mathrm{P}<0.01$ versus control group.

\section{Thermotherapy-induced expression of HSF1 proteins in 66 cells}

Expression of HSF1 was low and mainly occurred in the cytoplasm in the control group. After 30 min of thermotherapy, HSF1 immunoreactivity was found mainly in the nucleus (Figure 3A-F). The 30-min thermotherapy group exhibited a significant increase in HSF1 immunoreactivity. The mean optical density $(O D)$ value was $0.751 \pm 0.032$, higher than the value of $0.111 \pm 0.001$ in the control group $(P<0.01$, Figure $3 G)$. Subsequently the expression decreased gradually; after $180 \mathrm{~min}$ of thermotherapy, the expression was nearly identical to that in the control group. The integrated OD totals of HSF1 in the 10,30,60,120,180, and 240 min experimental thermotherapy groups were $0.204 \pm 0.011,0.751 \pm 0.032,0.623 \pm 0.053,0.436 \pm 0.805,0.327 \pm 0.708$, and 0.119 \pm 0.028 , respectively $(P<0.05, P<0.01)$, as shown in Figure 3G.
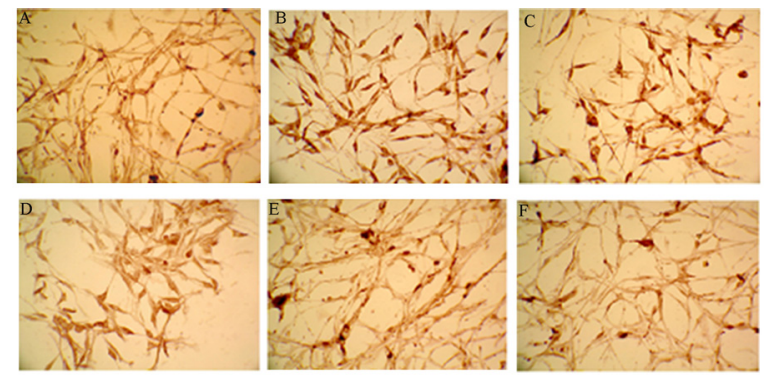

G

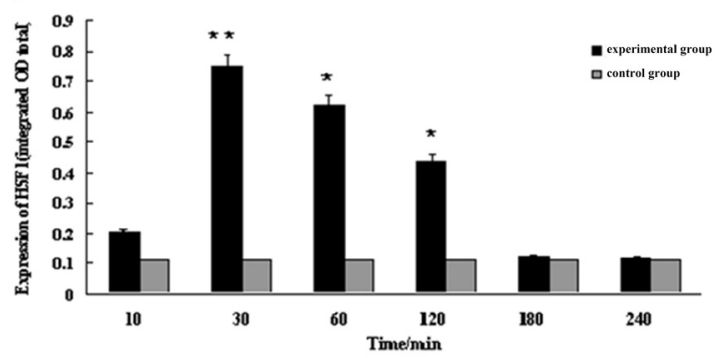

Figure 3. Expression of HSF1 in C6 cells after thermotherapy. Results of immunohistochemical investigation of HSF1 protein in the experimental and control groups after $10 \mathrm{~min}$ (A); $30 \mathrm{~min}$ (B); $60 \mathrm{~min}$ (C); $120 \mathrm{~min}$ (D); $180 \mathrm{~min}(\mathbf{E})$; or $240 \mathrm{~min}(\mathbf{F})$ thermotherapy. G. Relative expression levels of HSF1. ${ }^{*} \mathrm{P}<0.05$ and ${ }^{* *} \mathrm{P}<0.01$ versus control group. 


\section{Thermotherapy-induced reduction in tumor invasiveness}

The percentage of migrating cells was 1.8- to 4.4-fold lower in the thermotherapy groups than in the control group. Thermotherapy greatly reduced the number of migrating $\mathrm{C} 6$ cells after $120 \mathrm{~min}$ (Figure 4). The percentage of migrating cells in the 10, 30, 60, 120, 180, and $240 \mathrm{~min}$ groups were $25.2 \pm 0.3,24.1 \pm 0.5,15.0 \pm 0.4,10.1 \pm 0.2,20.0 \pm 0.6$, and $22.9 \pm 0.1$, respectively $(P<0.05, P<0.01)$, as shown in Figure 4.

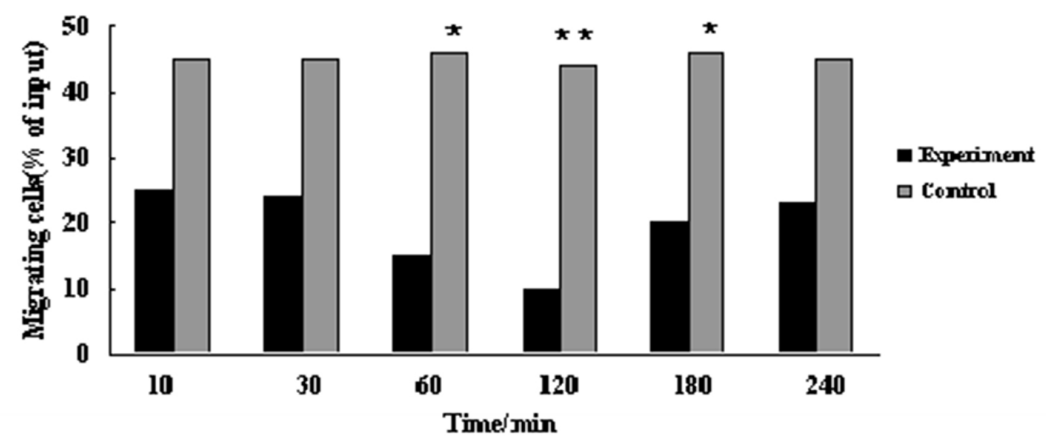

Figure 4. Thermotherapy-induced reduction in glioma invasiveness. C6 cells were subjected to thermotherapy for different lengths of time and compared with the control. $N=10$ for each time. ${ }^{*} \mathrm{P}<0.05$ and ${ }^{* *} \mathrm{P}<0.01$ versus control group.

\section{DISCUSSION}

These experiments show that thermotherapy can induce the transcription of TNF- $\alpha$ and peak transcription occurred 60 min after the C6 cells were subjected to thermotherapy (Figure 1). The levels of TNF- $\alpha$ protein reached a peak at 120 min (Figure 1A and B), suggesting that thermotherapy can directly and/or indirectly promote TNF- $\alpha$ transcription, protein translation, and release of the TNF- $\alpha$ protein into the extracellular environment. In addition, we found that thermotherapy $\left(42^{\circ} \mathrm{C}\right)$ induced a decrease in glioma invasiveness, which reached a minimum at 120 $\min$. At the same time, the concentration of TNF- $\alpha$ was at its highest (Figures 2 and 4). Therefore, it is quite possible that TNF- $\alpha$ expression and thermotherapy are correlated. The increase in TNF- $\alpha$ following thermotherapy further indicates that thermotherapy might stimulate TNF- $\alpha$ secretion in this process. This experiment confirmed that levels of TNF- $\alpha$ are consistent with decreases in glioma invasiveness, which further implies that thermotherapy decreases glioma invasiveness by enhancing the release of TNF- $\alpha$ from glioma cells. Therefore, thermotherapy can cause decreases in glioma invasiveness by inducing the secretion of TNF- $\alpha$. We conclude that thermotherapy can promote the release of TNF- $\alpha$ from glioma cells.

Our results showed that HSF1 expression increased and reached a peak at 30 min after the C6 cells were subjected to thermotherapy (Figure 3A-G). It is well known that the protective protein HSP70 is produced by stressed organisms. Thermotherapy, used to simulate heat stress, can induce the production of HSP70 in vivo (Singh et al., 2000; Skaggs et al., 2007). Moreover, HSP70 can be regulated by HSF1, which normally exists in the cytosol in an inactive state. In our opinion, thermotherapy activates HSF1, which induces HSP70 gene transcription (Togni et al., 
2010). In addition, the results showed that TNF- $\alpha$ transcription immediately increased, followed by translation, which peaked at 60 and $120 \mathrm{~min}$, respectively, after C6 cells were subjected to thermotherapy. Recently, it has been confirmed that there are many incomplete HSE sequences that are close to the 85-nucleotide non-translation sequence at the 5'-end of the TNF- $\alpha$ gene (Uzuka et al., 2006). We hypothesize that thermotherapy increases HSF1 protein expression. The HSF1 protein then combines with a HSE or its homoplastically similar sequence located upstream in the TNF- $\alpha$ and HSP70 genes, thereby affecting the expression of the TNF- $\alpha$ gene and increasing the synthesis and release of TNF-a protein. This leads to the decrease in glioma invasiveness. Our results also revealed that after $10 \mathrm{~min}$, there were differences in the levels of TNF- $\alpha \mathrm{mRNA}, \mathrm{TNF}-\alpha$ protein, and HSF1 protein, and a decrease in glioma invasiveness between the thermotherapy and control groups, both in vitro and in vivo, but the differences were not statistically significant.

In conclusion, our results show that thermotherapy-mediated decreases in glioma invasiveness are due to the accelerated release of TNF- $\alpha$, which may cause the decrease in glioma invasiveness by promoting the release of HSF1 from neurospongioma cells. The mechanism by which thermotherapy reduces glioma invasiveness is very complex. Besides HSP70, HSF1, and TNF- $\alpha$, other factors could be involved, and the process and regulation mechanisms warrant further investigation.

\section{Conflicts of interest}

The authors declare no conflict of interest.

\section{ACKNOWLEDGMENTS}

Research supported by the Natural Science Foundation of China (\#81101912 and \#81201048), the Hebei Province Department of Health and Family Planning Commission (\#20150491), and the Hebei Province Administration of Traditional Chinese Medicine (\#2014195).

\section{REFERENCES}

Cahill CM, Waterman WR, Xie Y, Auron PE, et al. (1996). Transcriptional repression of the prointerleukin 1beta gene by heat shock factor 1. J. Biol. Chem. 271: 24874-24879.

Chatterjee S, Premachandran S, Sharma D, Bagewadikar RS, et al. (2005). Therapeutic treatment with L-arginine rescues mice from heat stroke-induced death: physiological and molecular mechanisms. Shock 24: 341-347.

Du Y, Zhang D, Liu H and Lai R (2009). Thermochemotherapy effect of nanosized $\mathrm{As}_{2} \mathrm{O}_{3} / \mathrm{Fe}_{3} \mathrm{O}_{4}$ complex on experimental mouse tumors and its influence on the expression of CD44v6, VEGF-C and MMP-9. BMC Biotechnol. 9: 84.

Gourgou E, Aggeli IK, Beis I and Gaitanaki C (2010). Hyperthermia-induced Hsp70 and MT20 transcriptional upregulation are mediated by p38-MAPK and JNKs in Mytilus galloprovincialis (Lamarck); a pro-survival response. J. Exp. Biol. 213: 347-357.

Ivarsson K, Myllymäki L, Jansner K, Bruun A, et al. (2003). Heat shock protein 70 (HSP70) after laser thermotherapy of an adenocarcinoma transplanted into rat liver. Anticancer Res. 23: 3703-3712.

Iwasaki K, Rogers LR, Barnett GH, Estes ML, et al. (1993). Effect of recombinant tumor necrosis factor-alpha on threedimensional growth, morphology, and invasiveness of human glioblastoma cells in vitro. J. Neurosurg. 78: 952-958.

James JR, Gao Y, Soon VC, Topper SM, et al. (2010). Controlled radio-frequency hyperthermia using an MR scanner and simultaneous monitoring of temperature and therapy response by $(1) \mathrm{H},(23) \mathrm{Na}$ and (31) $\mathrm{P}$ magnetic resonance spectroscopy in subcutaneously implanted 9L-gliosarcoma. Int. J. Hyperther. 26: 79-90.

Jurivich DA, Pachetti C, Qiu L and Welk JF (1995). Salicylate triggers heat shock factor differently than heat. J. Biol. Chem. 270: 24489-24495.

Livak KJ and Schmittgen TD (2001). Analysis of relative gene expression data using real-time quantitative PCR and the 2- $-\Delta \Delta \mathrm{Ct}$ method. Methods 25: 402-408. 
Saito K, Kikuchi S, Hiroe A, Takahashi M, et al. (2005). Numerical Calculations of Heating Patterns around a Coaxial-Slot Antenna for Microwave Hyperthermia - Aiming at Treatment of Brain Tumor and Bile Duct Carcinoma. Conf. Proc. IEEE Eng. Med. Biol. Soc. 1: 478-481.

Schwerdt A, Zintchenko A, Concia M, Roesen N, et al. (2008). Hyperthermia-induced targeting of thermosensitive gene carriers to tumors. Hum. Gene Ther. 19: 1283-1292.

Senthil M and Harrison LE (2009). Simultaneous bicavitary hyperthermic chemoperfusion in the management of pseudomyxoma peritonei with synchronous pleural extension. Arch. Surg. 144: 970-972.

Singh IS, Viscardi RM, Kalvakolanu I, Calderwood S, et al. (2000). Inhibition of tumor necrosis factor-alpha transcription in macrophages exposed to febrile range temperature. A possible role for heat shock factor- 1 as a negative transcriptional regulator. J. Biol. Chem. 275: 9841-9848.

Skaggs HS, Xing H, Wilkerson DC, Murphy LA, et al. (2007). HSF1-TPR interaction facilitates export of stress-induced HSP70 mRNA. J. Biol. Chem. 282: 33902-33907.

Stummer W and Kamp MA (2009). The importance of surgical resection in malignant glioma. Curr. Opin. Neurol. 22: 645-649.

Suzuki M, Kato K, Mimoto N, Shindo Y, et al. (2010). SAR analysis of a re-entrant resonant cavity applicator for brain tumor hyperthermia treatment with a 3-D anatomical human head model. Conf. Proc. IEEE Eng. Med. Biol. Soc. 2010: 557-560.

Togni P, Vrba J and Vannucci L (2010). Microwave applicator for hyperthermia treatment on in vivo melanoma model. Med. Biol. Eng. Comput. 48: 285-292.

Uzuka T, Takahashi H and Tanaka R (2006). Interstitial hyperthermia with intra-arterial injection of adriamycin for malignant glioma. Neurol. Med. Chir. 46: 19-23. 